\title{
Total cover and cover quality: predicted and actual effects on a predator's foraging success
}

\author{
A Bartholomew \\ Virginia Institute of Marine Science
}

Follow this and additional works at: https://scholarworks.wm.edu/vimsarticles

Part of the Marine Biology Commons

\section{Recommended Citation}

Bartholomew, A, Total cover and cover quality: predicted and actual effects on a predator's foraging success (2002). MARINE ECOLOGY PROGRESS SERIES, 227, 1-9.

$10.3354 /$ meps 227001

This Article is brought to you for free and open access by the Virginia Institute of Marine Science at W\&M ScholarWorks. It has been accepted for inclusion in VIMS Articles by an authorized administrator of W\&M ScholarWorks. For more information, please contact scholarworks@wm.edu. 


\title{
Total cover and cover quality: predicted and actual effects on a predator's foraging success
}

\author{
Aaron Bartholomew* \\ Virginia Institute of Marine Science, Gloucester Point, Virginia 23062, USA
}

\begin{abstract}
I tested the importance of both total cover and cover quality to the foraging ability of large Fundulus heteroclitus fish in tanks. Total cover was measured as the combined areas of all the individual structures, viewed as shadows. I divided total cover by the bottom area of the tank to form $C_{\mathrm{t}} / A_{\mathrm{t}}$, an index that measures the total amount of structure available in a given area for prey to hide behind. Cover quality was measured as the width of each individual structure divided by the width of the individual prey organism $\left(C_{\mathrm{w}} / P_{\mathrm{w}}\right)$. This index measures how visible a prey organism is when hiding behind an individual structure. Both of these complexity indices are dimensionless and potentially applicable to any habitat type and habitat scale. I predicted that prey survivorship should increase hyperbolically with increasing $C_{\mathrm{t}} / A_{\mathrm{t}}$, because increasing the amount of structure within a habitat increases the amount of the habitat blocked off from detection, but with diminishing returns. Past experiments demonstrated that increased $C_{t} / A_{t}$ does increase prey survivorship, but the shape of the relationship was unclear. I also predicted that prey survivorship should increase hyperbolically with increasing $C_{\mathrm{w}} / P_{\mathrm{w}}$. I predicted this by simulating a prey organism hiding behind a flat structure being viewed by a predator from all potential angles. In this simple simulation, the 'average amount of the prey hidden from view' increased hyperbolically with increasing $C_{\mathrm{w}} / P_{\mathrm{w}}$ to an asymptote of 0.5 . I performed 2 experiments to test these ideas. In the first, I kept $C_{\mathrm{t}} / A_{\mathrm{t}}$ constant between treatments and varied the width of the individual structures relative to the width of shrimp prey Paleomonetes spp. In the second experiment, I kept the inter-structural space widths nearly constant between treatments and varied $C_{\mathrm{t}} / A_{\mathrm{t}}$. The prey for the second experiment were mobile amphipods. I tested the hypothesis that survivorship and treatment were independent using log-linear models for both experiments. I found that there was no significant difference in survivorship between treatments for the $C_{\mathrm{w}} / P_{\mathrm{w}}$ experiment, and there was a significant difference in survivorship between treatments for the $C_{\mathrm{t}} / A_{\mathrm{t}}$ experiment. The relationship between $C_{\mathrm{t}} / A_{\mathrm{t}}$ and prey survivorship appeared to increase hyperbolically, as predicted. Finally, I used the results of the $C_{\mathrm{t}} / A_{\mathrm{t}}$ experiment, and results from a past study, to form a modeled regression equation of the survivorship surface for large $F$. heteroclitus feeding on amphipods for various levels of $C_{\mathrm{t}} / A_{\mathrm{t}}$ and $S p / \operatorname{Pr}$ (inter-structural space size/predator width). This equation was highly significant, and fit the data well. In this regression, amphipod survivorship increased hyperbolically with increasing $C_{\mathrm{t}} / A_{\mathrm{t}}$, and decreased sigmoidally with increasing $\mathrm{Sp} / \mathrm{Pr}$.
\end{abstract}

KEY WORDS: Amphipods · Complexity - Cover - Dimensionless index · Fundulus heteroclitus · Habitat structure $\cdot$ Paleomonetes spp.

\section{INTRODUCTION}

Ecologists have long known that habitat structure often provides prey with refuges from predation in nature (Heck \& Wetstone 1977, Heck \& Thoman 1981, Orth et al. 1984). Unfortunately, ecologists have mea- sured and reported a wide variety of habitat parameters as 'complexity', which makes comparisons be-

\footnotetext{
${ }^{*}$ Present address: National Marine Fisheries Service, 75 Virginia Beach Drive, Miami, Florida 33149, USA. E-mail: aaron.bartholomew@worldnet.att.net
} 
tween studies difficult (Beck 1998, Attrill et al. 2000, Bartholomew et al. 2000). McCoy \& Bell (1991) state that 'habitat structure' encompasses the absolute abundance of habitat structural components (complexity), the relative abundances of different habitat structural components (heterogeneity), and the scale used to measure these. Recent experiments examining habitat-faunal interactions have recognized the importance of measuring habitat parameters that are meaningful to the specific organisms of concern, or otherwise scaling the measurements to the organisms of interest (Beck 1998, Attrill et al. 2000, Bartholomew et al. 2000). This paper discusses 2 indices of complexity that may be related to a predator's foraging success: the total amount of cover within a given area for prey to hide behind, and the size of the individual structures relative to the size of the prey. The latter index incorporates the scale of the organism of concern in a meaningful way.

Bartholomew et al. (2000) proposed the structural habitat complexity index $C_{\mathrm{t}} / A_{\mathrm{t}}$, which is the total cover area of all the structures within a given habitat divided by the area of the habitat itself. This index is dimensionless, is potentially (although not necessarily easily) applicable to all habitat types and scales, and may aid ecologists trying to compare results across studies. The 'cover area' of an individual structure would be akin to viewing the structure as a flat shadow, and measuring the area of the largest shadow that individual structure can produce.

As $C_{\mathrm{t}} / A_{\mathrm{t}}$ increases, more of the space within the habitat is obstructed from detection, and prey species have more structure to hide behind. However, as the number of individual structures increases, the functional redundancy of each additional structure, in terms of obstruction, would also increase. For example, imagine a habitat with a single structure. Adding another structure would obstruct more of the habitat from detection by a predator. The additional structure would also obstruct areas of the habitat already obstructed by the first structure, and vice versa, so the two would be functionally redundant to some extent. Increasing functional redundancy implies diminishing returns in the amount of space that is obstructed with increasing $C_{\mathrm{t}} / A_{\mathrm{t}}$. If prey survivorship is proportional to the amount of space that is obstructed from detection by predators, then this implies a hyperbolic relationship between $C_{\mathrm{t}} / A_{\mathrm{t}}$ and prey survivorship. Alternatively, certain predators, particularly those that pursue prey that are as fast or faster than they are and can easily detect the predators, may benefit from increased cover more than the prey. James \& Heck (1994) suggested that ambush predators in particular may benefit from increased cover, although they found no effect of increased complexity on the foraging success of the seahorse Hippocampus erectus, which they considered to be an ambush predator. Bartholomew et al. (2000) demonstrated that increasing $C_{\mathrm{t}} / A_{\mathrm{t}}$ led to increased prey survivorship, but were unable to demonstrate the shape of this relationship due to insufficient treatment range and the confounding effect of different interstructural space sizes relative to predator body width $(\mathrm{Sp} / \mathrm{Pr})$.

Another factor that may be important to prey survivorship is the cover quality of each individual structure, i.e. how large the structure is relative to the prey organism. For example, imagine a habitat with 5 structures that are 1 unit wide, and another habitat that has 1 structure that is 5 units wide. If there is a prey organism that is 1 unit wide it can, perhaps, effectively hide in both habitats, and its survivorship may be nearly equal in both habitats. If the prey organism is 5 units wide, however, it would always be at least partially visible in the habitat with narrow structures, but it could, perhaps, effectively hide behind the single, wider structure. Thus, prey survivorship may differ between the habitats for the larger prey, but not for the smaller.

To address the issue of cover quality, I devised the following dimensionless index: cover width/prey width $\left(C_{\mathrm{w}} / P_{\mathrm{w}}\right)$. The cover width is the largest width of an individual structure, again viewing the structure as a shadow, and the prey width is the appropriate linear dimension of the organism, depending upon how it hides behind structure. For example, grass shrimp Paleomonetes spp. grip vertically oriented, thin structures with their heads up or down (pers. obs.). Thus, the appropriate $P_{\mathrm{w}}$ to measure would be their width from side to side, as this is the dimension that would be revealed behind the structure, not their length from head to tail. Some amphipods, such as Gammarus mucronatus, tend to grip long, thin structures from the side, with their paraeopods downward (pers. obs.). In this case, the appropriate $P_{\mathrm{w}}$ to measure would be the head to telson length.

I performed a simple simulation to determine how the 'average amount of the prey hidden' varied with increasing $C_{\mathrm{w}} / P_{\mathrm{w}}$. I simulated an individual structure providing the cover as a line, and a prey organism hiding behind the structure as a circle tangent to the line at its midpoint (Fig. 1). The length of the line would be $C_{\mathrm{w}}$, and the diameter of the circle would be $P_{\mathrm{w}}$. The predator 'seeing' the prey was modeled as parallel light rays striking the prey and cover. I rotated the predator $360^{\circ}$ around the prey and cover, and measured the 'amount hidden' as the fraction of the prey's total diameter that would be in the shadow of the structure, i.e. the fraction hidden from view. The 'average amount hidden' for a given $C_{\mathrm{w}} / P_{\mathrm{w}}$ is the average fraction of the prey hidden from view as the predator is rotated $360^{\circ}$ around the prey (viewing the prey from all 
potential angles). I then performed this simulation for a variety of $C_{\mathrm{w}} / P_{\mathrm{w}}$ ratios, and I found the following:

The average amount of the prey hidden $=$

$$
\left[\left(C_{\mathrm{w}} / P_{\mathrm{w}}\right) /\left(1+C_{\mathrm{w}} / P_{\mathrm{w}}\right)\right] \times 0.5
$$

This is a hyperbolic relationship that has its asymptote at 0.5 , i.e. at very large $C_{\mathrm{w}} / P_{\mathrm{w}}$ values the predator is either on one side of the structure or the other, and has a $50 \%$ chance of seeing either the entire prey or none of the prey. If the total amount of the prey hidden is proportional to prey survivorship, then prey survivorship should increase hyperbolically with increasing $C_{\mathrm{w}} / P_{\mathrm{w}}$.

Different structural shapes may offer more or less protection to an individual prey relative to the flat plane in this simulation. A cylindrical structure of a given diameter, for example, would offer less protection than a flat plane of that width; alternatively, a curved structure that partially enclosed the prey would obviously offer more protection.

This simplistic model could also be complicated by prey behavior. If prey do not hide directly behind individual structures, prey survivorship would be less dependent on $C_{\mathrm{w}} / P_{\mathrm{w}}$. Conversely, prey may actively track the position of predators, and may change their position accordingly; thus, maximizing the amount of their body hidden behind a given structure (Main 1987). The activity level of the prey must be considered when applying this model. Relatively sedentary prey may rely more upon hiding behind individual structures for their survival than active prey, which may rely instead upon escape. Thus, $C_{\mathrm{w}} / P_{\mathrm{w}}$ may become increasingly relevant to organisms as their comparative activity levels decline, and $C_{\mathrm{w}} / P_{\mathrm{w}}$ may not be important to very active prey. In fact, wide structures may be disadvantageous to prey that rely upon active escape to avoid predation, as the wide structures may interfere with the prey's ability to detect potential predators. For example, Lima (1992) found that downy woodpeckers Picoides pubescens exhibited increasing vigilance behavior as the width of the tree trunks that they foraged on increased. He also found that the woodpeckers preferred thin or medium width trunks over wide trunks, presumably because the wider trees interfered more with their ability to detect potential predators (Lima 1992).

$C_{\mathrm{w}} / P_{\mathrm{w}}$ may also not be relevant to prey that rely upon other methods of predation avoidance besides hiding behind structures (such as noxiousness, camouflage, mimicry, etc.). $C_{\mathrm{w}} / P_{\mathrm{w}}$ may also not apply to fauna that do not hide behind structures, but, for example, hide by burying in sediments instead. The presence of multiple predators, prey and structures within a given habitat would also complicate this simplistic model.

I tested both of the predicted relationships between $C_{\mathrm{t}} / A_{\mathrm{t}}$ and $C_{\mathrm{w}} / P_{\mathrm{w}}$ with prey survivorship in experimen- tal tanks, where large Fundulus heteroclitus were used as predators, and mobile amphipods and shrimp Paleomonetes spp. were used as prey, respectively.

\section{MATERIALS AND METHODS}

All experiments were conducted in the Glucksman Experimental Mesocosm lab at the Virginia Institute of Marine Science, which has flow-through water from the York River and climate control. The plastic tanks used for the experiments were $36 \times 94 \times 22 \mathrm{~cm}$. They were filled, approximately $24 \mathrm{~h}$ before experimentation, to a depth of $15 \mathrm{~cm}$ with York River water that was filtered through a $250 \mu \mathrm{m}$ sieve to remove particles. The tanks had white paper taped to their sides, so that outside motions would not disturb the fish during the experiments. The lids had an $8 \times 8 \mathrm{~cm}$ opening for introducing prey and predators. The underside of the lids had ridged rubber mats secured to them to avoid the problem of shrimp jumping out of the water and sticking to the underside of the lid. The structural cover for both experiments was provided by $14 \mathrm{~cm}$ long, smooth, dark green ribbon, cut to the appropriate width, and secured to the bottom of the tanks with silicon aquarium adhesive. The ribbons were evenly spaced on the tank bottoms. Each tank was randomly assigned a position in a row along a lab table between experimental runs. Fundulus heteroclitus were the predators for both experiments, and were collected with minnow traps from a Spartina alterniflora marsh adjacent to the York River. They were kept in a tank with flow-through water for approximately 0 to $7 \mathrm{~d}$ before being placed in starvation tanks. The fish were fed live shrimp and live polychaetes while in captivity. I used 2 fish in each experimental run because in past tests a single fish did not consistently feed.

$\boldsymbol{C}_{\mathrm{w}} / \boldsymbol{P}_{\mathrm{w}}$. The habitat structural parameters for the 6 treatments are shown in Table 1. The total amount of cover/habitat area $\left(C_{\mathrm{t}} / A_{\mathrm{t}}\right)$ in each treatment was constant, and the inter-structural space size/predator body widths $(S p / P r)$ are all $>2.2$, the estimated 'threshold' value for Fundulus heteroclitus (Bartholomew et al. 2000). Below the threshold, the movement of the fish may be hampered by the smaller spaces, but at values above the threshold I assumed that different $S p / P r$ values had a negligible effect on predator maneuverability and prey survivorship. Note that in the treatments with wide structures the overall structural density is rather low, but this was necessary to have identical $C_{\mathrm{t}} / A_{\mathrm{t}}$ values for all the treatments and still have $\mathrm{Sp} / \mathrm{Pr}$ values $>2.2$ in the narrow structure treatments. The results of a prior experiment attempting to test the importance of $C_{\mathrm{w}} / P_{\mathrm{w}}$ using shrimp as prey and large 
Table 1. Structural habitat parameters, predator (fish) body size measurements, prey (shrimp) body size measurements and prey survivorship results for the cover width/prey width $\left(C_{\mathrm{w}} / P_{\mathrm{w}}\right)$ experiment

\begin{tabular}{|lcccccc|}
\hline Complexity treatment & 1 & 2 & 3 & 4 & 5 & 6 \\
\hline Avg inter-structural space size $(S p)(\mathrm{cm})$ & 4.0 & 4.5 & 5.4 & 6.6 & 9.2 & 11.7 \\
Avg fish gill to gill width $(P r)( \pm \mathrm{SE})(\mathrm{cm})$ & $1.4(0.0)$ & $1.4(0.0)$ & $1.4(0.0)$ & $1.4(0.0)$ & $1.4(0.0)$ & $1.4(0.0)$ \\
Avg $S p / \operatorname{Pr}( \pm \mathrm{SE})$ & $2.8(0.1)$ & $3.2(0.1)$ & $3.8(0.1)$ & $4.7(0.1)$ & $6.5(0.1)$ & $8.2(0.1)$ \\
No. of structures & 176 & 132 & 88 & 53 & 26 & 11 \\
Individual structure width $\left(C_{\mathrm{w}}\right)(\mathrm{cm})$ & 0.15 & 0.20 & 0.30 & 0.50 & 1.00 & 2.40 \\
Total structural cover area/tank area $\left(C_{\mathrm{t}} / A_{\mathrm{t}}\right)$ & 0.1 & 0.1 & 0.1 & 0.1 & 0.1 & 0.1 \\
Avg shrimp width $\left(P_{\mathrm{w}}\right)(\mathrm{cm})( \pm \mathrm{SE})$ & $0.41(0.01)$ & $0.41(0.01)$ & $0.41(0.01)$ & $0.41(0.01)$ & $0.41(0.01)$ & $0.40(0.01)$ \\
Structure width/shrimp width $\left(C_{\mathrm{w}} / P_{\mathrm{w}}\right)( \pm \mathrm{SE})$ & $0.37(0.01)$ & $0.49(0.01)$ & $0.75(0.01)$ & $1.25(0.02)$ & $2.50(0.03)$ & $6.09(0.08)$ \\
'Avg amount $(\%)$ of the prey hidden' (from Eq. 1) & 14 & 16 & 21 & 28 & 36 & 43 \\
No. of survivors/total no. of shrimp exposed & $26 / 88$ & $27 / 90$ & $35 / 90$ & $36 / 90$ & $30 / 92$ & $21 / 91$ \\
Avg \% survivorship per run $( \pm \mathrm{SE})$ & $30(7)$ & $30(7)$ & $39(9)$ & $40(7)$ & $33(8)$ & $23(6)$ \\
\hline
\end{tabular}

F. heteroclitus as predators was hopelessly confounded because low $C_{\mathrm{w}} / P_{\mathrm{w}}$ treatments also had $S p / P r$ values below the threshold level.

Experiments were conducted in June and July 2000. I used fish $>8 \mathrm{~cm}$ in length for this experiment. Paleomonetes spp. were the prey in this experiment, and were collected with a dip net from a Spartina alterniflora marsh adjacent to the York River and held in a glass aquarium prior to experimentation. Shrimp were fed on commercial flake food and were fed and measured immediately before transfer to the tanks. Fish were starved for 38 to $40 \mathrm{~h}$ before experimentation in a tank resembling the experimental tanks. The fish were randomly assigned to a treatment and transferred to small mesh bags suspended from the openings of the tanks for 30 min before release. This allowed the fish to acclimate without eating the shrimp, which were added to the tanks immediately before the fish. The fish were then released to feed on the 5 shrimp for approximately $4.5 \mathrm{~h}$. I used 5 shrimp and $4.5 \mathrm{~h}$ exposure times in each run of this experiment because in preliminary tests large $F$. heteroclitus could eat 5 shrimp in tanks without any cover in approximately $4.5 \mathrm{~h}$. Thus, any survivorship I observed in the treatments was probably due to the habitat structure, and not due to the fish being satiated. After the experiment, the fish were removed from the tanks, their widths were measured, and the surviving shrimp were recovered and counted. Note that shrimp routinely jumped out of the water and stuck to the inner sides of the tanks. These shrimp were not counted as 'survived' or 'eaten' for that treatment, and I would use 6 shrimp in a subsequent run of the same treatment to keep the total number of shrimp counted approximately equal between treatments.

The survivorship results for all of the 18 experimental runs in each treatment were pooled, and I analyzed the results using log-linear modeling in SAS. I used this statistical test because of the problems with different numbers of shrimp used in each experimental run (discussed above). In this analysis each shrimp is treated as a single replicate with the possible binomial response 'survived' or 'eaten' (Agresti 1990). The null hypothesis was that prey survivorship is independent of $C_{\mathrm{w}} / P_{\mathrm{w}}$ treatment type.

$\boldsymbol{C}_{\mathbf{t}} / \boldsymbol{A}_{\mathbf{t}}$. The habitat structural parameters for the 6 treatments in this experiment are shown in Table 2. Note that the $S p / P r$ values of these treatments are nearly equal and above the threshold value of 2.2 for Fundulus heteroclitus. Experiments were conducted in

Table 2. Structural habitat parameters, predator (fish) body size measurements and prey (amphipod) survivorship results for the total cover/tank area $\left(C_{\mathrm{t}} / A_{\mathrm{t}}\right)$ experiment

\begin{tabular}{|lcccccc|}
\hline Complexity treatment & 1 & 2 & 3 & 4 & 5 & 6 \\
\hline Avg inter-structural space size $(\mathrm{Sp})(\mathrm{cm})$ & 4.0 & 4.1 & 4.1 & 4.0 & 4.1 & 4.1 \\
Avg fish gill to gill width $(\operatorname{Pr})( \pm \mathrm{SE})(\mathrm{cm})$ & $1.3(0.0)$ & $1.3(0.0)$ & $1.3(0.0)$ & $1.3(0.0)$ & $1.3(0.0)$ & $1.3(0.0)$ \\
Avg $S p / \operatorname{Pr}( \pm \mathrm{SE})$ & $3.1(0.0)$ & $3.2(0.1)$ & $3.2(0.0)$ & $3.1(0.1)$ & $3.2(0.0)$ & $3.2(0.0)$ \\
No. of structures & 176 & 161 & 161 & 161 & 138 & 105 \\
Individual structure width $(\mathrm{cm})$ & 0.1 & 0.2 & 0.3 & 0.5 & 1.0 & 2.4 \\
Total structural cover area/tank area $\left(C_{\mathrm{t}} / A_{\mathrm{t}}\right)$ & 0.07 & 0.13 & 0.20 & 0.33 & 0.57 & 1.04 \\
No. of survivors/total no. of amphipods exposed & $19 / 144$ & $33 / 144$ & $37 / 144$ & $50 / 144$ & $53 / 144$ & $61 / 144$ \\
Avg no. of survivors per run $( \pm \mathrm{SE})$ (max $=16)$ & $2.1(0.8)$ & $3.7(1.1)$ & $4.1(1.4)$ & $5.6(1.8)$ & $5.9(1.8)$ & $6.8(1.8)$ \\
& & & & & & \\
\hline
\end{tabular}


August and September of 2000. I used fish $>7.5 \mathrm{~cm}$ length in this experiment. I collected amphipods from artificial seagrass plots deployed in a seagrass bed in the York River, Virginia. All the amphipods used in the experiments were active, epifaunal species. I did not identify each individual amphipod I used, but the majority of them were Gammarus mucronatus, Ampithoe spp., and Cymadusa compta. Amphipods were kept 1 to $24 \mathrm{~h}$ prior to experimentation in buckets placed in a flow-through tank that received water from the York River. Each bucket had holes with mesh over them that allowed some water exchange. I used amphipods in this experiment to be consistent with the methodology of Bartholomew et al. (2000). I used shrimp, rather than amphipods, in the $C_{\mathrm{w}} / P_{\mathrm{w}}$ experiment (above) because I needed treatments with small $C_{\mathrm{w}} / P_{\mathrm{w}}$ values, and it would have been difficult to make the very thin structures necessary to produce small $C_{\mathrm{w}} / P_{\mathrm{w}}$ values using small amphipods. Fish were starved for $24 \mathrm{~h}$ prior to experimentation in a tank similar to the experimental tanks. Fish were randomly assigned to a treatment, and were placed in a mesh bag suspended from the top for 30 min before release to allow the fish to acclimate. Amphipods were randomly added to the tanks immediately before the fish, and each amphipod was observed to determine whether they were appropriately 'active' or not. Amphipods that did not immediately swim when put in the tanks or exhibit an escape response when gently nudged were replaced. Each experimental run had 16 amphipods. The 2 fish were allowed to feed on the amphipods for $75 \mathrm{~min}$, similar to Bartholomew et al. (2000). I chose this number of amphipods, and this exposure time because I found that 2 starved $F$. heteroclitus of this size can consistently eat 16 amphipods in 75 min in tanks with no structure (Bartholomew et al. 2000). Thus, any survivorship I observed was probably due to the structure, and not due to the fishes' satiation. After $75 \mathrm{~min}$ the fish were removed from the tanks, their gill to gill width was measured, and the surviving amphipods were counted.

The survivorship results from the 9 experimental runs were pooled, and I analyzed the results using loglinear modeling in SAS. I used categorical data analysis in this experiment because of anticipated heterogeneous variances between treatments. The null hypothesis was that prey survivorship is independent of $C_{\mathrm{t}} / A_{\mathrm{t}}$ treatment. To help analyze the shape of the relationship, I plotted the estimated first derivative of $C_{\mathrm{t}} / A_{\mathrm{t}}$ and survivorship versus $C_{\mathrm{t}} / A_{\mathrm{t}}$ in similar way to Bartholomew et al. (2000).

Using the data from this experiment, and from the 3 lab experiments in Bartholomew et al. (2000), I plotted the 'survivorship surface' of $S p / P r$ and $C_{t} / A_{t}$ versus prey survivorship (similar to Bartholomew et al. 2000,

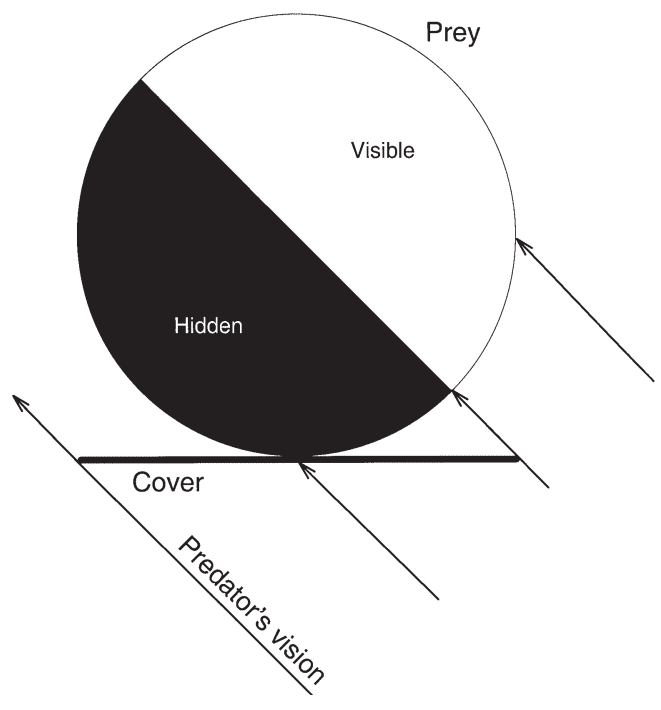

Fig. 1. Example of the simulation used to determine the relationship between cover width/prey width $\left(C_{\mathrm{w}} / P_{\mathrm{w}}\right)$ and the 'average amount of the prey hidden'. The cover is a simple line, and the prey is a circle tangent to the line at its midpoint. The predator's vision is simulated as parallel light rays striking the cover-prey complex. In this example, $C_{\mathrm{w}} / P_{\mathrm{w}}=1$; the predator is viewing the prey from a $45^{\circ}$ angle, and the prey is $50 \%$ hidden. If the predator were viewing the prey from all angles simultaneously in this example, the prey would, on average, be $25 \%$ hidden

their Fig. 1). I used these data to form the simplest regression model that fit the data and accounted for the shapes of the relationships between $C_{t} / A_{t}, S p / P r$ and prey survivorship. $S p / P r$ is the average inter-structural space size divided by the gill-to-gill width of the fish in this case. It is dimensionless, and measures the extent to which the spaces within the habitat affect the maneuverability of the fish. Bartholomew et al. (2000) found that prey survivorship decreases in a 'threshold', or sigmoidal, manner with increasing $\mathrm{Sp} / \mathrm{Pr}$.

\section{RESULTS}

$$
\boldsymbol{C}_{\mathrm{w}} / \boldsymbol{P}_{\mathrm{w}}
$$

Different numbers of shrimp were exposed to the predators due to the problem of shrimp jumping out of the water and sticking to the sides of the tanks (Table 1). This problem may have affected my results in unexpected ways, as shrimp that stuck to the sides and later returned to the water before the end of the experiment may have been counted as survivors. Thus, some caution should be used when interpreting these results. The percent survival data was arc-sine transformed to calculate the standard error, and then back 
transformed (Table 1). The results of the log-linear model (Table 3) fail to reject the null hypothesis that survivorship and treatment level are independent $(\mathrm{p}=$ 0.15). The results (Table 1 ) indicate a slight peak of survivorship at intermediate $C_{\mathrm{w}} / P_{\mathrm{w}}$ values, although again there is no significant difference between treatments.

\section{$C_{\mathrm{t}} / \boldsymbol{A}_{\mathrm{t}}$}

The results of the experiment are shown in Table 2 . The results of the log-linear model (Table 4) reject the null hypothesis that treatment level and survivorship are independent $(p<0.00005)$. Thus, the different levels of $C_{t} / A_{t}$ in the different treatments affected the survivorship of the amphipods. The graph of the results
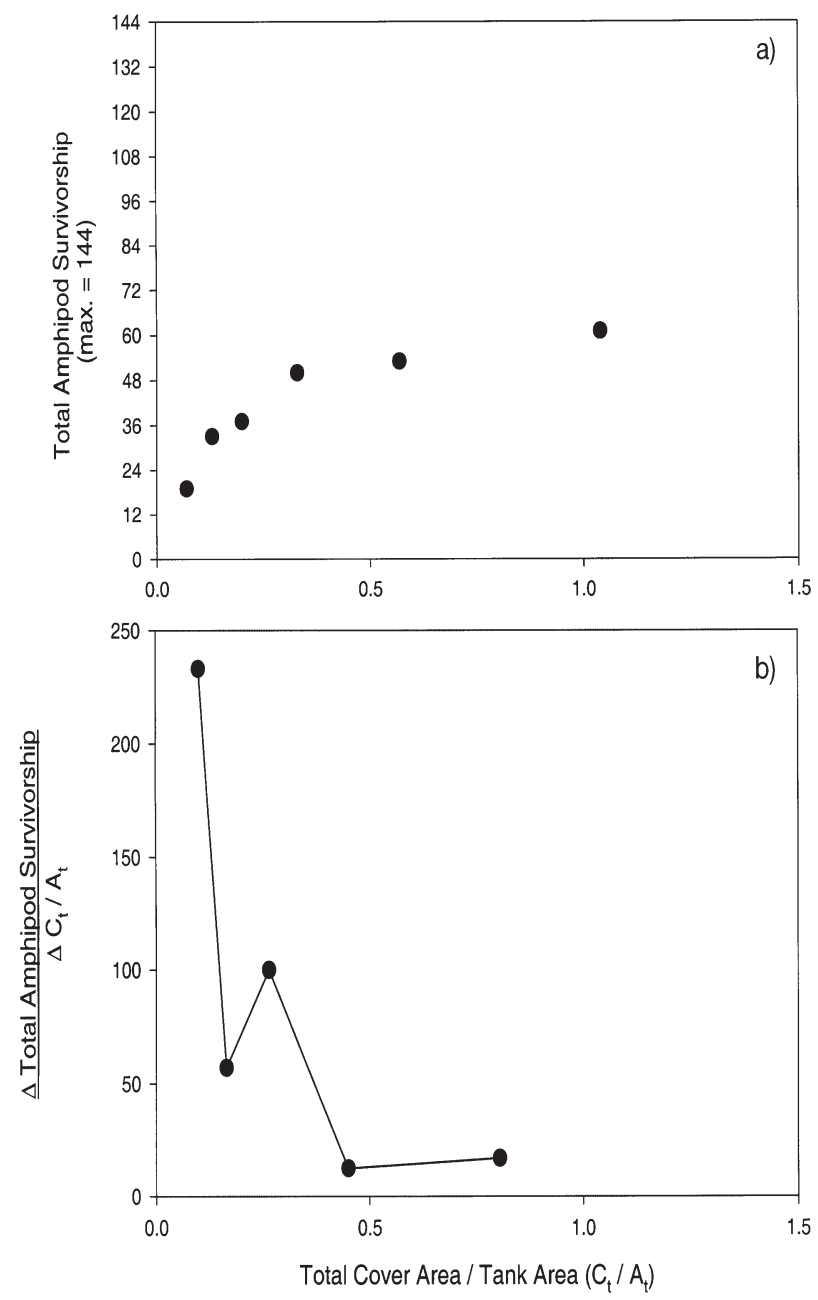

Fig. 2. (a) Results of the total cover/tank area $\left(C_{\mathrm{t}} / A_{\mathrm{t}}\right)$ experiment. (b) Estimated first derivative of the second experimental results graphed versus $C_{\mathrm{t}} / A_{\mathrm{t}}$. Position along the $x$-axis is the midpoint of the $2 C_{\mathrm{t}} / A_{\mathrm{t}}$ values used to estimate each first derivative value and the first derivative of the results indicate a generally hyperbolic relationship between $C_{\mathrm{t}} / A_{\mathrm{t}}$ and prey survivorship, as predicted (Fig. 2a,b).

The 3-dimensional graph of the combined $S p / P r$ and $C_{\mathrm{t}} / A_{\mathrm{t}}$ versus percent prey survivorship data from this experiment and from Bartholomew et al. (2000) is shown in Fig. 3a,b, along with the modeled regression surface. The equation for this regression surface is

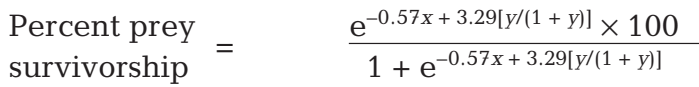

where $x=S p / P r$ and $y=C_{t} / A_{t}$. Note that a control treatment with $C_{\mathrm{t}} / A_{\mathrm{t}}=0$ (no structure) had $0 \%$ survivorship, but was omitted from this analysis because it could not be assigned an $S p / P r$ value. Both of the parameters, -0.57 and 3.29 , are highly significant $(\mathrm{p}<$ 0.0001 for both), and the overall regression is highly significant $(\mathrm{df}=1, F=184.69, \mathrm{p}<0.0001)$. The adjusted $\mathrm{r}^{2}$ for this regression is 0.90 . This regression equation is the simplest, best fitting equation in which percent survivorship increased hyperbolically with increasing $C_{\mathrm{t}} / A_{\mathrm{t}}$ and decreased sigmoidally with increasing $S p / P r$. More complex equations had parameters that were not significant. Simpler equations that did not account for the shapes of the relationships between $C_{\mathrm{t}} / A_{\mathrm{t}}, S p / \operatorname{Pr}$ and prey survivorship did not fit the results as well.

\section{DISCUSSION}

I found that increasing the width of individual structures relative to the width of shrimp prey (increasing $C_{\mathrm{w}} / P_{\mathrm{w}}$ ) while keeping the total amount of cover within a tank divided by the area of the tank $\left(C_{\mathrm{t}} / A_{\mathrm{t}}\right)$ constant had no effect on shrimp survivorship. The results of the $C_{\mathrm{t}} / A_{\mathrm{t}}$ experiment support the idea that prey survivorship increases hyperbolically with increasing $C_{\mathrm{t}} / A_{\mathrm{t}}$, if inter-structural space size divided by predator width $(S p / P r)$ is kept nearly constant. I used the results from the $C_{\mathrm{t}} / A_{\mathrm{t}}$ experiment, and from the 3 laboratory experiments in Bartholomew et al. (2000), to form a regres-

Table 3. Maximum likelihood log-linear model for the cover width/prey width $\left(C_{\mathrm{w}} / P_{\mathrm{w}}\right)$ experiment. The interaction between treatment and survival tests the null hypothesis that these factors are independent, a significant result indicates non-independence

\begin{tabular}{|lcrc|}
\hline Source & df & Chi-square & Probability \\
\hline Treatment & 5 & 1.13 & 0.9510 \\
Survival & 1 & 65.03 & 0.0000 \\
Treatment $\times$ Survival & $\mathbf{5}$ & $\mathbf{8 . 1 7}$ & $\mathbf{0 . 1 4 7 2}$ \\
\hline
\end{tabular}


sion model for large, starved Fundulus heteroclitus feeding on 16 mobile amphipods for 75 min with various $C_{t} / A_{t}$ and $S p / P r$ levels. This modeled regression fit the results quite well and was highly significant.

The $C_{\mathrm{w}} / P_{\mathrm{w}}$ simulation (Fig. 1) predicted that differences in cover width relative to prey width between treatments should affect prey survivorship, but the results did not support this model. The proposed simulation may have been too simplistic to be successfully applied to this experiment. The simulation was based upon a single animal hiding directly behind a single structure and being observed by 1 predator. My experiment was more complex, however, with multiple structures, prey and predators. Furthermore, the shrimp used in this experiment were fairly mobile; in preliminary observations they often hid behind individual structures, behaving like the prey in my simulation, but they also crawled or swam about frequently. I may have observed a relationship between prey survivorship and $C_{\mathrm{w}} / P_{\mathrm{w}}$ if I had used a more sedentary prey species that was more dependent upon hiding to avoid predation. Shrimp jumping out of the water and sticking to the sides of the tanks was also an unfortunate complicating factor, and the effect this may have had on my results is unknown.

The simulation predicted that shrimp survivorship should increase hyperbolically with increasing $C_{\mathrm{w}} / P_{\mathrm{w}}$ but the observed trend was that the lowest survivorship was observed in the highest width treatment. This suggests that something other than the 'amount of the prey hidden' behind an individual structure may have been important. The high $C_{\mathrm{w}} / P_{\mathrm{w}}$ treatment had the lowest numbers of individual structures, and also the widest spaces between individual structures. Perhaps the low survivorship in this treatment was due to the fish having fewer structures to search behind when looking for prey, or because there was more open space between structures to be detected in if shrimp tried to move from structure to structure. If the latter is true, then this would be another reason that high $\mathrm{Sp} / \mathrm{Pr}$ levels in habitats would be disadvantageous to prey. It is interesting that the highest survivorship occurred in the treatment with $0.5 \mathrm{~cm}$ width, having a $C_{\mathrm{w}} / P_{\mathrm{w}}$ near 1 . This treatment had the most individual structures available that the shrimp could be completely hidden behind at least part of the time. Again, however, there were no significant differences between treatments, which indicates that $C_{\mathrm{w}} / P_{\mathrm{w}}$ may not be as important to prey survivorship as $C_{\mathrm{t}} / A_{\mathrm{t}}$ and $S p / P r$.

Others have found that prey hiding behind individual structures affects their survivorship (Main 1987) and that the width of habitat structure, relative to prey size, had an effect on predator-prey interactions. Kenyon et al. (1995) demonstrated that a smaller proportion of prawn Panaeus escalentus were detected by
Table 4. Maximum likelihood log-linear model for the total cover/tank area $\left(C_{t} / A_{t}\right)$ experiment. The interaction between treatment and survival tests the null hypothesis that these factors are independent, a significant result indicates nonindependence

\begin{tabular}{|lcrc|}
\hline Source & df & Chi-square & Probability \\
\hline Treatment & 5 & 8.21 & 0.1449 \\
Survival & 1 & 141.15 & $<0.00005$ \\
Treatment $\times$ Survival & $\mathbf{5}$ & $\mathbf{3 7 . 2 0}$ & $<\mathbf{0 . 0 0 0 0 5}$ \\
\hline
\end{tabular}
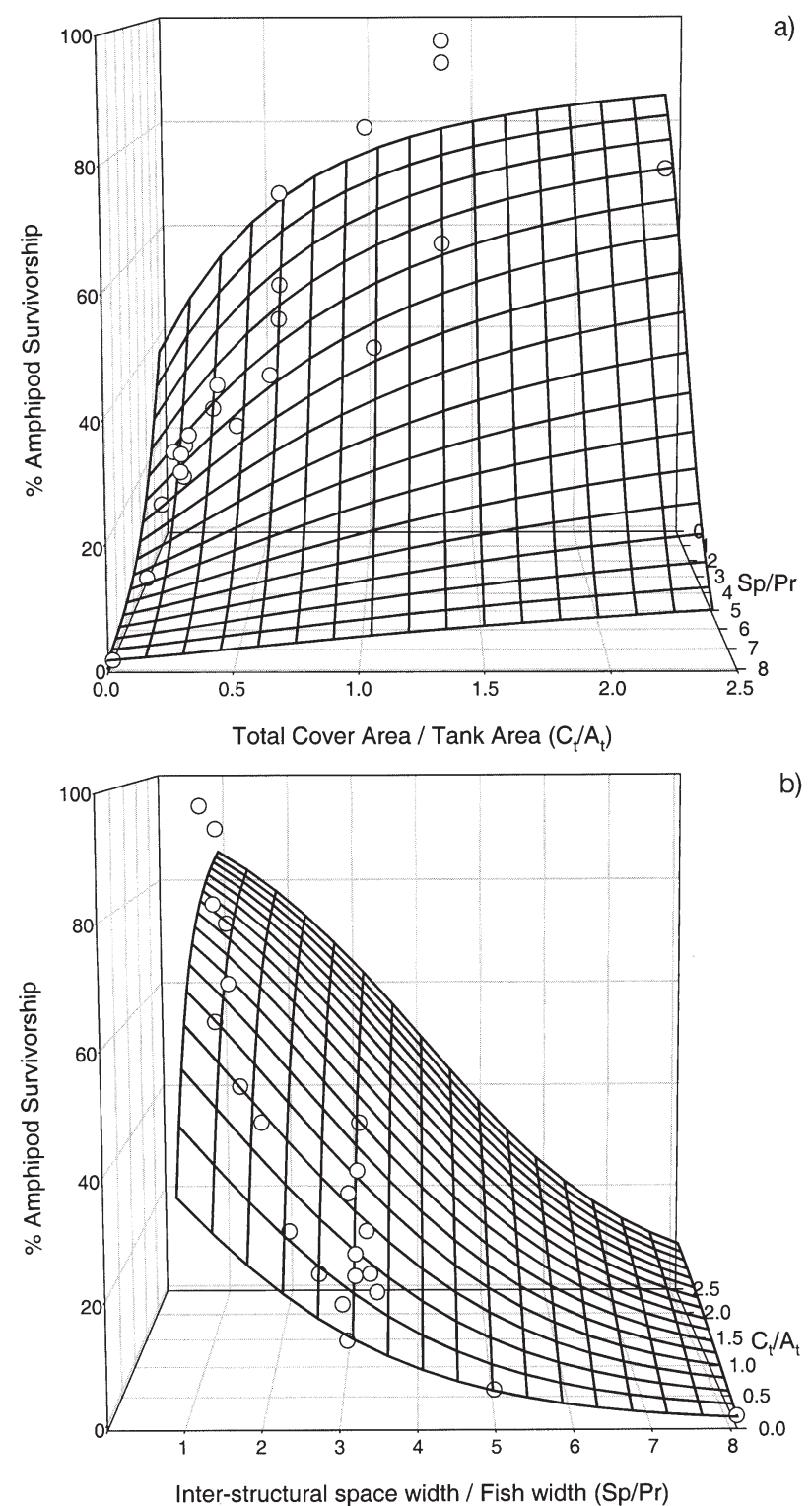

Fig. 3. (a) Three-dimensional plot of the results of the $C_{\mathrm{t}} / A_{\mathrm{t}}$ experiment, combined with the results of the Bartholomew et al. (2000) lab experiments, and the modeled regression surface, viewed from the $C_{\mathrm{t}} / A_{\mathrm{t}}$ axis. (b) The same, viewed from the $S p / P r$ axis. See text for the regression surface equation 
a fish predator Psammoperca waigiensis in wide bladed seagrass Cymodocea serrulata (10 mm width) as compared with the narrow bladed species Halodule uninervis (1 mm width) and Syringodium isoetifolium (2 mm width). The proportion of prawns eaten was lower in C. serrulata as well, although this difference was not significant. Kenyon et al. (1995) also found that different sized $P$. esculentus behaved differently in treatments with different seagrass widths. Small (1 mm width) prawns were equally likely to perch on $H$. uninervis and C. serrulata, as opposed to burying in the substrate. Larger (10 mm width) prawns were significantly less likely to perch on $H$. uninervis than on $C$. serrulata, as opposed to burying in the substrate. Kenyon et al. (1995) noted that $H$. uninervis provides a good refuge from visual predators only for small juveniles, whereas $C$. serrulata provides a good refuge for both size classes. In another study, Kenyon et al. (1997) found that $P$. esculentus selected $C$. serrulata over $S$. isoetifolium, which in turn was preferred over $H$. uninervis and shortened $S$. isoetifolium. Kenyon et al. (1997) suggest that this active selection of habitat type may explain the distribution of $P$. esculentus in nature.

Stoner (1982) found that narrow Halodule wrightii blades provided less refuge than wider Thalassia testudinum blades for amphipods being preyed upon by the visual predator Lagodon rhomboides. This pattern appeared to be important in explaining the field distribution of amphipods as well, because epifaunal species and larger individuals were less abundant in $H$. wrightii beds compared with T. testudium beds (Stoner 1983).

The hyperbolic relationship found between $C_{\mathrm{t}} / A_{\mathrm{t}}$ and prey survivorship supports the model proposed by Bartholomew et al. (2000). That study found that increasing $C_{\mathrm{t}} / A_{\mathrm{t}}$ increased prey survivorship, but was unable to determine the shape of the relationship, due to the confounding effect of different $S p / P r$ levels, and insufficient range of $C_{\mathrm{t}} / A_{\mathrm{t}}$ values. In this study, $S p / P r$ was kept relatively constant, and the range of $C_{\mathrm{t}} / A_{\mathrm{t}}$ values between 0.07 and 1.04 was sufficient to detect the relationship shape.

Other researchers have found hyperbolic relationships between 'complexity' and prey survivorship, although they all measured complexity differently, and probably did not account for any differences in $\mathrm{Sp} / \mathrm{Pr}$ between treatments. For example, Lipcius et al. (1998) found a hyperbolic relationship between increasing algal biomass and increasing survivorship for both small and large Caribbean spiny lobsters Panulirus argus. Similarly, Schulman (1996) found a hyperbolic survivorship curve for large juvenile blue crabs Callinectes sapidus with increasing artificial seagrass densities. Graham et al. (1998) also found that amphipod survivorship increased in a hyperbolic manner with increasing artificial eelgrass densities when exposed to Fundulus heteroclitus.

Modeling the results from this study, and those from Bartholomew et al. (2000) produced a survivorship regression surface that fit the results quite well, and has the appropriate shapes with increasing $C_{\mathrm{t}} / A_{\mathrm{t}}$ and $S p / P r$. The good fit illustrates that the survivorship results between experiments were fairly consistent for a given $S p / P r$ and $C_{t} / A_{t}$ level, despite differences in amphipod prey species, time of year and structure type between experiments. Note that the $C_{\mathrm{t}} / A_{\mathrm{t}}$ and $S p / P r$ treatments used to form this regression are generally high $C_{\mathrm{t}} / A_{\mathrm{t}}$ and low $S p / P r$, low $C_{\mathrm{t}} / A_{\mathrm{t}}$ and high $S p / P r$ or intermediate values for both (Fig. $3 a, b)$, and the gaps in experimental treatment levels may affect the predictions of the regression. For example, at very low $C_{\mathrm{t}} / A_{\mathrm{t}}$ levels and at low $S p / P r$ levels near 1, where there are no actual data, the regression predicts a survivorship of less than $40 \%$. However, at such low $S p / P r$ levels the fish would barely be able to move through the spaces to catch prey, and actual prey survivorship would probably be substantially higher, despite the low cover.

The shapes of the relationships between $S p / P r$ and $C_{\mathrm{t}} / A_{\mathrm{t}}$ to prey survivorship lead to some interesting and important predictions about habitat structure-predator-prey interactions. Adding structure to a habitat with no cover will increase prey survivorship rapidly, but after a certain point adding further structure will make little difference in prey survivorship $\left(C_{\mathrm{t}} / A_{\mathrm{t}}\right.$ asymptote reached), as long as the threshold value for $S p / P r$ is not obtained. The hyperbolic $C_{\mathrm{t}} / A_{\mathrm{t}}$ survivorship curve may reach an asymptote that is substantially less than $100 \%$ survivorship, so the prey may never achieve an 'absolute' refuge from predation. For example, in this experiment, the survivorship curve was approaching an asymptote of approximately $50 \%$ survivorship (Fig. 2a), and the amphipods were only exposed for $75 \mathrm{~min}$. Adding structure to a habitat can substantially increase prey survivorship if the threshold value for $S p / P r$ is crossed. At $S p / P r$ values that are low enough, prey can achieve a more absolute refuge from predation, because even if the predators can see the prey, they may not be able to fit through the habitat spaces to catch the prey. For example, the highest percent survivorship in the $C_{\mathrm{t}} / A_{\mathrm{t}}$ experiment was $42 \%$ in the highest cover treatment $\left(C_{\mathrm{t}} / A_{\mathrm{t}}=1.04\right)$. Other treatments in Bartholomew et al. (2000) with comparable $\left(C_{\mathrm{t}} / A_{\mathrm{t}}=0.99\right)$ and even less amount of cover $\left(C_{\mathrm{t}} / A_{\mathrm{t}}\right.$ $=0.59$ ) had higher percent survivorship (80 and 68\%, respectively) because they had lower $S p / P r$ values (1.21 and 1.50, respectively) than the highest cover treatment in this experiment $(S p / P r=3.2)$. This is an interesting prediction from this model: habitats with greater amounts of cover may provide prey with worse 
refuge from predation than habitats with less cover, if the habitats with less cover have $S p / P r$ values that are below the threshold value, and the habitat with more cover does not. Habitats with appropriately low $S p / P r$ values are more likely to provide an absolute refuge from predation than habitats with only high $C_{\mathrm{t}} / A_{\mathrm{t}}$ values. These indices of habitat complexity and the shapes of their relationships with prey survivorship may be useful to consider for researchers interested in manipulating natural structures or constructing artificial structures for predator and prey organisms, and for researchers assessing the relative refuge values of various natural structures.

Acknowledgements. I would like to thank my advisor Dr Robert Diaz and T. V. Padma for their continuous support. Thanks to Dr Diaz, Dr Mark Patterson and 3 anonymous reviewers for providing helpful comments on this manuscript. I was supported by a US EPA STAR fellowship-Thank you very much! This is VIMS contribution No. 2406.

\section{LITERATURE CITED}

Agresti A (1990) Categorical data analysis. Wiley-Liss, New York

Attrill MJ, Strong JA, Rowden AA (2000) Are macroinvertebrate communities influenced by seagrass structural complexity? Ecography 23:114-121

Bartholomew A, Diaz RJ, Cicchetti G (2000) New dimensionless indices of structural habitat complexity: predicted and actual effects on a predator's foraging success. Mar Ecol Prog Ser 206:45-58

Beck MW (1998) Comparison of the measurement and effects of habitat structure on gastropods in rocky intertidal and mangrove habitats. Mar Ecol Prog Ser 169:165-178

Graham S, Davis J, Deegan L, Cebrian J, Hughes J, Hauxwell $J$ (1998) Effect of eelgrass (Zostera marina) density on the feeding efficiency of mummichog (Fundulus heteroclitus). Biol Bull 195:241-243

Heck KL Jr, Thoman TA (1981) Experiments on predator-prey

Editorial responsibility: Otto Kinne (Editor),

Oldendorf/Luhe, Germany interactions in vegetated aquatic habitats. J Exp Mar Biol Ecol 53:125-134

Heck KL Jr, Wetstone GS (1977) Habitat complexity and invertebrate species richness and abundance in tropical seagrass meadows. J Biogeogr 4:135-142

James PL, Heck KL Jr (1994) The effects of habitat complexity and light intensity on ambush predation within a simulated seagrass habitat. J Exp Mar Biol Ecol 176:187-200

Kenyon RA, Loneragan NR, Hughes JM (1995) Habitat type and light affect sheltering behavior of juvenile tiger prawns (Panaeus esculentus Haswell) and success rate of their fish predators. J Exp Mar Biol Ecol 192:87-105

Kenyon RA, Loneragan NR, Hughes JM, Staples DJ (1997) Habitat type influences the microhabitat preference of juvenile tiger prawns (Panaeus esculentus Haswell and Panaeus semisulcatus DeHaan). Estuar Coast Shelf Sci 45: 393-403

Lima SL (1992) Vigilance and foraging substrate: antipredator considerations in a non-standard environment. Behav Ecol Sociobiol 30:283-289

Lipcius RN, Eggleston DB, Miller DL, Luhrs TC (1998) The habitat-survival function for Caribbean spiny lobster: an inverted size effect and non-linearity in algal and seagrass habitats. Mar Freshw Res 149:807-816

Main KL (1987) Predator avoidance in seagrass meadows: prey behavior, microhabitat selection, and cryptic coloration. Ecology 68:170-180

McCoy ED, Bell SS (1991) Habitat structure: the evolution and diversification of a complex topic. In: Bell SS, McCoy ED, Mushinsky HR (eds) Habitat structure, the physical arrangement of objects in space. Chapman and Hall, New York, p 3-27

Orth RJ, Heck KL Jr, Van Montfrans J (1984) Faunal communities in seagrass beds: A review of the influence of plant structure and prey characteristics on predator-prey relationships. Estuaries 7:339-350

Schulman J (1996) Habitat complexity as a determinant of juvenile blue crab survival. MSc thesis, The College of William and Mary, Gloucester Point, VA

Stoner A (1982) The influence of benthic macrophytes on the foraging behavior of pinfish, Lagodon rhomboides (Linneus). J Exp Mar Biol Ecol 58:271-284

Stoner A (1983) Distributional ecology of amphipods and tanaidaceans associated with three seagrass species. J Crustac Biol 3:505-518

Submitted: June 1, 2001; Accepted: August 31, 2001

Proofs received from author(s): February 4, 2002 